\title{
The Predictive Power of Concurrent Pulse Oximetry Readings in the Detection of Congenital Heart Defects in Newborns of the Hospital of Specialties of Children and Woman in Queretaro, Mexico
}

Oscar San Roman Orozco, Wiliam Nkemdirim, Isidro A Gutierrez Alvarez, Annamarie Saarinen, Enzo Zanella, Juan E Muñoz, Patricia Ledesma, L. Alejandra Guzman, Brenda M Perez

\begin{abstract}
:
In Mexico, CHD incidence is estimated at 18,000-21,000 newborns per year, and at least $25 \%$ will have critical congenital heart disease. The mortality rates showed that $24 \%$ of the infant deaths in 2013 were attributable to CCHDs. Despite these, the CCHD screening is not performed in all hospitals. The general objective is to show the statistical relationships, compared with existing evidence of the power of repeat screenings on detection of CCHD, to better inform government recommendations for universal screening in Mexico. Three thousand seven pulse oximetry readings were performed on newborns (the 5th of February - the 1st of July of 2019). We aimed to perform the first screen on the subjects between 5-48 hrs of life. Some required a repeat reading due to a failure in the first. Screenings occurred between 6-69 hrs, with a mean time of $22 \mathrm{hr}$ post-delivery. Secondary readings were performed on 160, of which 29 were also given echocardiograms because they failed the secondary test. The average measurement on the foot was $93.8 \%$ and on the right hand was $93.5 \%$. In the 29 subjects with repeated readings, seven were positive for CCHD; two were false positives.
\end{abstract}

The data and analysis show promise in the association between early readings and the detection of potential CCHD. There is a correlation between the concerning readings and detection of CCHD through an echocardiogram. More data is needed to ascertain other relationships, but the results thus far imply low pulse oximetry readings associated with CCHDs and other secondary conditions associated with hypoxemia.

Keywords: Pulse oximetry; Critical Congenital Heart Disease; Screening

\section{Introduction}

Congenital heart defects (CHDs) are the most common types of birth defects. (4) In the United States, $1 \%$ of newborns have congenital heart disease, and of these, at least a quarter will have a critical congenital heart disease (CCHD) that will be reflected by the need for early management or surgical intervention in the first weeks or months of life. $(2,4)$. Such diseases are a primary cause of death in the first year of life $(25 \%)$ and the leading cause of acute cardiac failure in the neonatal period. (1) Among newborns with $\mathrm{CCHD}, 40 \%$ will have a significant defect who will require cardiologic treatment and possible surgical treatment.

Newborn screening for CCHD based on pulse-oximetry readings can help earlier detect otherwise asymptomatic critical and severe heart defects associated with hypoxemia (5). This tool's importance relies on the fact that when performed correctly, it can detect subclinical levels of hypoxemia that should raise suspicion for CCHD (5).

According to Thangaratinam et al. 2012 (8), they reviewed 552 studies and chose 13 to form a cohort study of 229,421 newborns in which it was determined that this screening performed within the first $24 \mathrm{hrs}$ of life had $76.5 \%$ sensitivity and $99.9 \%$ specificity. The study had a $0.14 \%$ false-positive rate. Pulse oximetry screening poses great specificity for detecting a CCHD with an acceptable sensitivity inside the criteria for Universal Screening programs.

\section{"Our focus here on this overall index rather than on the individual morbidity outcomes reflected an attempt to use the most statistically robust outcome for our present analysis."}

In Mexico, the congenital heart disease incidence in newborns is estimated at 18,000 to 21,000 live newborns. Mexico's mortality trends from (1998-2013) showed that $24 \%$ of the infant deaths in 2013 were attributable to congenital anomalies, and CHD represented $55 \%$ of total deaths from congenital anomalies among children under one year of age. (6) Additionally, at least 25\% of CHD cases are being diagnosed after their hospital discharge. (3) Of these, 1,000 to 4,500 newborns will have critical congenital heart disease. In 2013, a total of 3,593 deaths from CHD occurred in Mexico: approximately $10 \%$ occurred on the first day of life. (6)

Pulse-oximetry screening protocols have been developed and implemented to avoid the delayed diagnosis of hypoxemia that often escapes the clinical eye. Screening is based on the reading of the oxygen saturation (SpO2) in the pre and post-ductal limbs during a period after birth, but before hospital discharge - before the signs of congenital heart disease become present. (4) Despite the importance so far shown, in Queretaro, Mexico, there is still no strict and official regulation that makes it mandatory for all

NEONATOLOGY TODAY is interested in publishing manuscripts from Neonatologists, Fellows, NNPs and those involved in caring for neonates on case studies, research results, hospital news, meeting announcements, and other pertinent topics.

Please submit your manuscript to: LomaLindaPublishingCompany@gmail.com 
hospitals to use pulse oximetry screening. The only official recommendation exists for premature newborns. (12)

Objective: Based on the results of a screening program, the statistical relationships, and comparing them with the literature surrounding CCHD screening, we attempt to build upon the recommendation for the government to require newborn $\mathrm{CCHD}$ screening as a permanent program in the newborn nursery for all babies before discharge. This has been incorporated via screening of the right hand and either foot at one of the largest maternity hospitals in the state, Hospital of Specialties of Children and Woman in Queretaro, Mexico.

Specific objectives: (1) Evaluate the association between early pulse oximetry readings and the detection of potential cardiogenic defects. (2) Assess the feasibility of implementation of a CCHD screening program through pulse oximetry in the State of Queretaro

\section{"When we re-analyzed the data for the mortality/morbidity index for the risk difference (RD), the chosen random- effects model provided a similar overall value for this as the fixed effect models (RD of 0.13 and 0.14 respectively) with similar significance."}

\section{Materials and Methods}

This research followed the CCHD screening algorithm utilized by the BORN Project (Birth Oximetry Routine for Newborns) from the Newborn Foundation. $(9,11)$ This protocol is based on the algorithm endorsed by the AAP, AHA, ACC, and March of Dimes in the United States. $(10,11)$ Interestingly, the BORN Project algorithm varied from the AAP protocol by using a single re-screen for those babies with a positive first screen. An expert panel recently updated its recommendations in alignment with this protocol. (13)

The equipment used was portable pulse-oximeters based on a cell phone app (Masimo iSpO2rx). This equipment is not yet FDA cleared for $\mathrm{CCHD}$ screening but is certified to measure SpO2 in movement and/or low perfusion conditions. The required app is free of charge, available for iOS and Android (Masimo Health). (11).

The algorithm was designed for use in the well-child newborn nursery. It indicates that screening should be performed at $>24$ hours of age or before discharge on the right hand and either foot $(9,10,11)$. The procedure for performing the screen is divided into ten steps based on the Newborn Foundation Guidelines (11).

\section{1) Assemble all equipment.}

2) Connect the pulse oximeter and sensor cords together.

3) Place the $\mathrm{YI}$ sensor probes into the wrap.

(4) On either of the baby's feet, position the two sensors opposite each other on the foot's outer aspect.

5) When the signal quality is strong and steady, record the $\mathrm{SpO} 2$ reading from the baby's foot.

6) Place the sensor on the baby's right hand and position the probes directly opposite each other on the fleshy outer aspect of the hand.

7) When the signal quality is strong and steady, record the $\mathrm{SpO} 2$ reading from the baby's right hand.

8) A passed screening requires a reading greater than or equal to $95 \%$ on both the hand and foot with a difference of no more than $3 \%$.

9) A Reading on either the hand and foot between $90-94 \%$ or a difference greater than $3 \%$ between the two is considered failing and requires a second screening in 15 minutes. If the second screening yields similar results, the screening is considered failed, and a primary care physician must be notified.

10) Readings from either the hand or foot equal or less than $89 \%$ indicate a failed screening and require a primary care physician to be urgently notified.

The data was collected by hand on a spreadsheet by the nurses who performed the screen. The project team was retrieved the data from the hospital and uploaded it to a secure database in the cloud for analytical purposes. The sample gathered for this research included 3007 babies who were both asymptomatic and cared for by their mothers in their room between the 5th of February of 2019 and the 1st of July of 2019.

The protocols establish that an echocardiogram must be performed to determine the exact diagnosis after failing the first and second pulse oximetry readings. No echos were done after the first reading, only after the second.

The data were computed and analyzed through Stata Statistical Software.

\section{Results}

Simple linear regression analysis examined several relationships between first-round hand pulse oximetry readings and echocardiogram results, between second round pulse oximetry readings and echocardiogram results.

First and second round readings distributions were fairly normal. The dependent and independent variables had a somewhat linear relationship; residuals were linear and equally distributed.

Three thousand seven first-round pulse oximetry readings were performed on all subjects. Secondary pulse oximetry readings were performed on 160 of these, of which 29 also had an echocardiogram based on pulse oximetry readings (Table 1). The aim was to perform first-round screenings on the subjects between 5 hrs of life to $48 \mathrm{hrs}$; on the subjects that required a repeat pulse oximetry reading, screenings occurred between 6 and $69 \mathrm{hrs}$, with a mean time of $22 \mathrm{hr}$ post-delivery and a standard deviation of $11.5 \mathrm{hr}$. No statistically or clinically significant correlation was evident between screening time and echocardiogram results. (Table 1)

The average pulse oximetry measurement on the foot was $93.8 \%$ $(95 \%(\mathrm{Cl})=98 \%, 89.5 \%)$, in the right hand, it was $93.5 \%(95 \%$ $(\mathrm{Cl})=98.5 \%, 87.5 \%)$. Regression models were created to compare the different groups in the study.

One hundred sixty babies required additional pulse oximetry testing, of which 29 did not pass and had to be re-screened a second time. These patients had an echocardiogram. The mean pulse oximetry reading in the second round of screening was $94.1 \%$ $(95 \%(\mathrm{Cl})=98 \%, 88 \%)$. Out of the 29 with repeated pulse oximetry readings, echocardiograms were performed, resulting in 7 positive results, of which 2 were false positives. 
Table 1. This table shows the distribution of echocardiogram results by gender, age, and pulse oximetry

\begin{tabular}{|l|l|l|l|l|l|l|}
\hline Variable & observations & Mean & Std. Dev. & Min & Max & Variable \\
\hline Gender (1) & 29 & .7241379 & .4548588 & 0 & 1 & 29 \\
\hline Age & 29 & 19.7931 & 8.570628 & 7 & 47 & 29 \\
\hline SpO2_round1_hand & 29 & .9337931 & .0408319 & .8 & 1 & 29 \\
\hline SpO2_round1_foot & 29 & .922069 & .0353936 & .84 & .99 & 29 \\
\hline Echo(2) & 29 & .0689655 & .2578807 & 0 & 1 & 29 \\
\hline SpO2_round2_hand & 29 & .9413793 & .0341973 & .85 & 1 & 29 \\
\hline SpO2_round2_foot & 29 & .9451724 & .0311243 & .85 & .99 & 29 \\
\hline
\end{tabular}

(1)0 is temale, 1 is male(2) 0 is a negative echo, 1 is a positive

Regression analysis was performed on numerous parameters, which showed statistical significance. However, the overall Radjusted values indicated that, as significant as the observations were, there is potentially a variable of such strength that would better explain the observed correlation than the observed pulse oximetry readings. Results indicate that first-round pulse oximetry readings were positively correlated to second round pulse oximetry readings. $(b=0.422$, SEb $=0.200, \beta=0.376, t=2.11 p<.044)$ (Table 2). The $95 \%$ confidence intervals around the regression coefficient were narrow $(0.011,0.834)$, indicating acceptable precision. The effect was relatively weak, with $10.9 \%$ of the variance in $\mathrm{SpO} 2$ readings in round two accounting for $\mathrm{SpO} 2$ readings from round 1 .

This correlation coefficient above 0 allows the rejection of the hypothesis that the pulse oximetry readings in round 1 and round 2 are equal, suggesting a directional difference in the two readings.

\section{"However, we were concerned that}

\section{this analysis was not an accurate}

representation of the data. Our own

analysis utilized the authors' data on individual morbidities to calculate the average number of adverse events per subject. There were 31 adverse events in 64 subjects fed HMDF (0.48 events per subject); yet, for CMDF there were 45 adverse events among 61 subjects $(0.74$ events per subject)."

The echocardiogram results were compared to the second round of screening SpO2 readings using a multivariate regression analysis. Results indicate that second round pulse oximetry readings were positively correlated to echocardiogram results (which were split into 0 for negative echocardiogram results, and 1 for positive echocardiogram results) (Table 4$)$. (b1 $=-3.78$, SEb $=3.36, \beta=$ $-0.313, t=-1.12 p<.271),(b 2=-5.89$, SEb $=3.69, \beta=-0.445$, $\mathrm{t}=-1.60 \mathrm{p}<.122)$. The $95 \%$ confidence intervals around the regression coefficient (b1: -10.688, 3.127), (b2:-13.485, 1.695). The effect was relatively weak, though with $50.06 \%$ of the variance in $\mathrm{SpO} 2$ readings in the two round two tests accounted for echocardiogram results. Although there was a discernible effect size, the effect was statistically insignificant and highlights the study's need for more statistical power.

More interesting, is the weaker association between $\mathrm{SpO} 2$ readings from the first round of screening and echocardiogram positive results (table 3 ). ( $b 1=-3.819, \mathrm{SEb}=2.42, \beta=-0.355, \mathrm{t}=-1.58 \mathrm{p}$ $<.127),(\mathrm{b} 2=-0.689$, SEb $=2.95, \beta=-0.0 .52, \mathrm{t}=-0.23 \mathrm{p}<.817$ ). The $95 \%$ confidence intervals around the regression coefficient (b1: -8.797, 1.15), (b2:-6.76, 5.386). The effect was relatively weak and with a low effect size, though, with $8.6 \%$ of the variance in $\mathrm{SpO} 2$ readings in round two accounted for echocardiogram results.

\section{Discussion}

Out of 3007 pulse oximetry readings, 160 required repeated screening readings, and finally, an echocardiogram $(n=29)$. The results show an increased need for statistical power, as the positive echocardiogram results are quite a few.

Multivariate regression analysis showed small effect sizes and statistically insignificant associations. However, based on univariate analysis, particularly in the second-round screenings, the findings are more significant.

In modeling first-round hand pulse oximetry readings against echocardiogram results, there is a statistically significant difference that allows the rejection of the hypothesis that there is no association between oximetry readings and echocardiogram results. $(t=-2.18, p=0.038)$. This allows the position that the two variables are correlated, though weakly as suggested above. Such a conclusion cannot be said for the first round, SpO2 readings obtained from the foot $(t=1.43, p=0.165)$.

Although there is a statistically significant difference between the

NEONATOLOGY TODAY is interested in publishing manuscripts from Neonatologists, Fellows, NNPs and those involved in caring for neonates on case studies, research results, hospital news, meeting announcements, and other pertinent topics.

Please submit your manuscript to: LomaLindaPublishingCompany@gmail.com 
Table 2. This table shows readings in subjects that received both the echocardiogram and second-round pulse oximetry

\begin{tabular}{|l|l|l|l|l|l|}
\hline & Coeff & $\begin{array}{l}\text { Standard } \\
\text { error }\end{array}$ & $T$ & $P>|t|$ & $\begin{array}{l}95 \% \text { confi- } \\
\text { dence interval }\end{array}$ \\
\hline $\begin{array}{l}\text { SpO2 round } \\
2 \text { hand }\end{array}$ & 0.422 & 0.200 & 2.11 & 0.044 & $0.012,0.833$ \\
\hline Constant & 0.529 & 0.188 & 2.81 & 0.009 & $0.143,0.916$ \\
\hline
\end{tabular}

$R$-squared $=0.1416$

Adjusted R-squared $=0.110$

Table 3. Multiple regression of the first-round hand and foot $\mathrm{SpO} 2$ readings and echo results

\begin{tabular}{|l|l|l|l|l|l|}
\hline & Coeff & $\begin{array}{l}\text { Standard } \\
\text { error }\end{array}$ & $\mathrm{T}$ & $\mathrm{P}>|\mathrm{t}|$ & $\begin{array}{l}\text { 95\% Confi- } \\
\text { dence interval }\end{array}$ \\
\hline $\begin{array}{l}\text { SpO2 round } \\
1 \text { hand }\end{array}$ & -3.820 & 2.422 & -1.58 & 0.127 & $-8.797,1.158$ \\
\hline $\begin{array}{l}\text { SpO2 round } \\
1 \text { foot }\end{array}$ & -0.689 & 2.96 & -0.23 & 0.817 & $-6.765,5.386$ \\
\hline Constant & 4.382 & 2.269 & 1.93 & 0.064 & $-0.281,9.046$ \\
\hline
\end{tabular}

$R$-squared $=0.1515$

Adjusted R-squared $=0.086$

Table 4. Multiple regression of the second-round hand and foot $\mathrm{SpO} 2$ readings and echo results

\begin{tabular}{|l|l|l|l|l|l|}
\hline & Coeff & $\begin{array}{l}\text { Standard } \\
\text { error }\end{array}$ & $T$ & $P>|t|$ & $\begin{array}{l}\text { 95\% Confi- } \\
\text { dence interval }\end{array}$ \\
\hline $\begin{array}{l}\text { SpO2 round } \\
2 \text { hand }\end{array}$ & -3.781 & 3.361 & -1.12 & 0.271 & $-10.789,3.127$ \\
\hline $\begin{array}{l}\text { SpO2 round } \\
2 \text { foot }\end{array}$ & -5.895 & 3.692 & -1.60 & -.122 & $\begin{array}{l}-13.485, \\
1.6953\end{array}$ \\
\hline Constant & 9.335 & 1.665 & 5.61 & 0.000 & $5.913,12.757$ \\
\hline
\end{tabular}

$R$-squared $=0.542$

Adjusted R-squared $=0.5066$

Table 5. Regression model between first-round hand pulse oximetry reading and echocardiogram results

\begin{tabular}{|l|l|l|l|l|l|}
\hline & Coeff & Standard error & $\mathrm{T}$ & $\mathrm{P}>|\mathrm{t}|$ & beta \\
\hline Echo & -0.036 & 0.0165 & -2.18 & 0.038 & -0.387 \\
\hline
\end{tabular}

$R$-squared $=0.1497$

Adjusted R-squared $=0.118$ 
able 6. Regression model of round 1-foot pulse oximetry readings and echocardiogram results

\begin{tabular}{|l|l|l|l|l|l|}
\hline & Coeff & $\begin{array}{l}\text { Standard } \\
\text { error }\end{array}$ & $\mathrm{T}$ & $\mathrm{P}>|\mathrm{t}|$ & $\begin{array}{l}\text { 95\% confi- } \\
\text { dence interval }\end{array}$ \\
\hline $\begin{array}{l}\text { SpO2 round } \\
\text { foot }\end{array}$ & -3.477 & 2.43 & -1.43 & 0.165 & $-8.470,1.516$ \\
\hline Constant & 3.409 & 2.242 & 1.52 & 0.140 & $-1.192,8.010$ \\
\hline
\end{tabular}

$R$-squared $=0.0703$

Adjusted R-squared $=0.0 .0359$

Table 7. Regression model of round 2-foot pulse oximetry readings and echocardiogram results

\begin{tabular}{|l|l|l|l|l|l|}
\hline & Coeff & $\begin{array}{l}\text { Standard } \\
\text { error }\end{array}$ & $T$ & $P>|t|$ & $\begin{array}{l}\text { 95\% confi- } \\
\text { dence interval }\end{array}$ \\
\hline $\begin{array}{l}\text { SpO2 round } \\
2 \text { foot }\end{array}$ & -9.547 & 1.767 & -5.40 & 0.000 & $-13.17,-5.92$ \\
\hline Constant & 9.228 & 1.67 & 5.52 & 0.000 & $5.801,12.65$ \\
\hline
\end{tabular}

$R$-squared $=0.520$

Adjusted R-squared $=0.502$

Table 8. Regression model of round 2 hand pulse oximetry readings and echocardiogram results

\begin{tabular}{|l|l|l|l|l|l|}
\hline & Coeff & Standard error & $T$ & $\mathrm{P}>|\mathrm{t}|$ & Beta \\
\hline Echo & -0.058 & 0.011 & -5.16 & 0.000 & -0.705 \\
\hline Constant & 0.953 & 0.005 & 185.13 & 0.000 & \\
\hline
\end{tabular}

$R$-squared $=0.497$

Adjusted R-squared $=0.478$

Table 9. Correlation between the right-hand readings in round 1 vs. round 2

\begin{tabular}{|l|l|l|l|l|l|l|}
\hline Variable & observations & Mean & Std. Dev. & Min & Max & Variable \\
\hline Gender (1) & 29 & .7241379 & .4548588 & 0 & 1 & 29 \\
\hline Age & 29 & 19.7931 & 8.570628 & 7 & 47 & 29 \\
\hline SpO2_round1_hand & 29 & .9337931 & .0408319 & .8 & 1 & 29 \\
\hline SpO2_round1_foot & 29 & .922069 & .0353936 & .84 & .99 & 29 \\
\hline Echo(2) & 29 & .0689655 & .2578807 & 0 & 1 & 29 \\
\hline SpO2_round2_hand & 29 & .9413793 & .0341973 & .85 & 1 & 29 \\
\hline SpO2_round2_foot & 29 & .9451724 & .0311243 & .85 & .99 & 29 \\
\hline
\end{tabular}

(1) 0 is female, 1 is male

(2) 0 is a negative echo, 1 is positive 
second-round hand $\mathrm{SpO} 2$ readings, they are highly correlated. $(\mathrm{t}=$ -5.16, $p=0.000)$. Nevertheless, as mentioned $(n=29)$, there is a need for increased statistical power. For the second-round foot readings, the results were again significant $(t=-5.4, p=0.000)$

The model also shows that chance of a positive echocardiogram reading increases with every $5.44 \%$ decrease in the $\mathrm{SpO} 2$ round 2 test reading.

Compared to first-round readings, which suggest that every $3.6 \%$ decrease in pulse oximetry readings increases the chance of a positive echo on more in-depth analysis, as the first-round reads accounted for $11.8 \%$ of observed variance, decreases in oxygenation are less correlated with an instance of CCHD.

As the newborns did not have echocardiograms after first-round readings, the results support the importance of two oxygenation screens before echocardiogram to reduce false positives and increase the true predictive power of pulse oximetry readings for CHD.

Only seven were positive in the babies subjected to repeated pulse oximetry readings $(n=29)$ and a subsequent echocardiogram. It was later ascertained that two were false positives. The results suggest a lack of correlation between initial pulse oximetry readings and a positive echo for CCHD. However, there is a correlation between the second round of pulse oximetry readings and possible CCHD, which suggests the need for a tiered pulse oximetry screening protocol. Univariate and multivariate logistic models give nonsignificant, near-0, odds ratios.

\section{Conclusions}

The data and analysis show promise in the association between early pulse oximetry readings and the detection of potential cardiogenic defects. There is a correlation between the concerning readings and detection of cardiogenic defects through an echocardiogram. More data is needed to ascertain other possible relationships, such as the timing of the pulse oximetry readings, gender associations. However, the results thus far imply that low pulse oximetry readings on the initial screen are correlated with potential CCHD.

A large sample is needed to ascertain why there is a univariate association between the second round $\mathrm{SpO} 2$ readings and potential echo results, compared to first-round $\mathrm{SpO} 2$ readings, which are statistically insignificant and boasting small effect sizes, alongside the multivariate relationships, which are also statistically insignificant.

The reported rates show that $1 \%$ of live newborns will have a CHD. (12) For this protocol, we fully screened 160 newborns and, from which 2 were FP; this suggests a rate of $5 / 160$, which is higher than the reported rates. The implications of this are that perhaps, newborns are not screened well enough in general, or the rates in the studied city are above normal.

Either way, a calculation of statistical power is required for better ascertainment and efficacy evaluation. This study also suggests a need for additional studies with a defined statistical power and the inclusion of more parameters, including the timing of first and last round pulse oximetry readings to determine why the secondround readings were more closely associated with positive echocardiogram results.

\section{References:}

1. Khalil, M., Jux, C., Rueblinger, L., Behrje, J., Esmaeili, A., \& Schranz, D. (2019). Acute therapy of newborns with critical congenital heart disease. Translational pediatrics, 8(2), 114-126. doi:10.21037/tp.2019.04.06
2. Badawi, D., Watson, J., Maschke, S., \& Reid, L. (2019). First-Year Outcomes of Critical Congenital Heart Disease Screening in Maryland. Global pediatric health, 6, 2333794X19868226. doi:10.1177/2333794X19868226

3. Brown KL, Ridout DA, Hoskote A, Verhulst L, Ricci M, Bull $C$. Delayed diagnosis of congenital heart disease worsens preoperative condition and outcome of surgery in neonates. Heart.2006; 92: 1298-1302.

4. National Center on Birth Defects and Developmental Disabilities, Centers for Disease Control and Prevention. https:// www.cdc.gov/ncbddd/heartdefects/data.html. Page last reviewed: the 12th of November, 2019.

5. Engel, M. S., \& Kochilas, L. K. (2016). Pulse oximetry screening: a review of diagnosing critical congenital heart disease in newborns. Medical devices (Auckland, N.Z.), 9, 199-203. doi:10.2147/MDER.S102146

6. Torres-Cosme JL, Rolón-Porras C, Aguinaga-Ríos M, Acosta-Granado PM, Reyes- Muñoz E, Murguía-Peniche T (2016) Mortality from Congenital Heart Disease in Mexico: A Problem on the Rise. PLoS ONE 11(3): e0150422. doi:10.1371/ journal.pone.0150422

7. Jiménez-Carbajal, M.G., Pérez, D.L., \& Luna, C.P. (2018). Relevancia de la detección de cardiopatías congénitas complejas mediante cribado con oximetría de pulso en recién nacidos aparentemente sanos en los establecimientos de salud. https://doi.org/10.1016/j.acmx.2018.02.001

8. Thangaratinam, S., Brown, K., Zamora, J., Khan, K. S., \& Ewer, A. K. (2012). Pulse oximetry screening for critical congenital heart defects in asymptomatic newborn babies: a systematic review and meta-analysis. Lancet, 379(9835), 2459-2464. doi:10.1016/S0140-6736(12)60107-X

9. Oster, M. E., Aucott, S. W., Glidewell, J., Hackell, J., Kochilas, L., Martin, G. R., . . Kemper, A. R. (2016). Lessons Learned From Newborn Screening for Critical Congenital Heart Defects. Pediatrics, 137(5). doi:10.1542/peds.20154573

10. de-Wahl Granelli A, Wennergren M, Sandberg K, et al. Impact of pulse oximetry screening on the detection of duct dependent congenital heart disease: a Swedish prospective screening study in 39, 821 newborns. BMJ. 2009; 338:a3037. (PubMed: 19131383)

11. Newborn Foundation Resource Hub. http://www.newbornfoundation.org/born-project/data

12. Guia de Practica Clinica: Manejo del Recien Nacido Prematuro Sano hospitalizado. Instituto Mexicano del Seguro Social. Catalogo Maestro de Guias de Practica Clinica IMSS362-18.

13. Martin, G. R., Ewer, A. K., Gaviglio, A., Hom, L. A., Saarinen, A., Sontag, M., Oster, M. E. (2020). Updated Strategies for Pulse Oximetry Screening for Critical Congenital Heart Disease. Pediatrics, 146(1), e20191650. doi:10.1542/ peds.2019-1650

Author Contributions: Conceptualization, O.S.R and I.G.A.; methodology, O.S.R, I.G.A and W.N; software, W.N.; validation, W.N., O.S.R and A.S.; formal analysis, O.S.R and W.N.; investigation, A.S.; resources, A.S.; data curation, E.Z, J.M, P.L, A.G and B.P.; writing-original draft preparation, O.S.R and W.N.; writing-review and editing, I.G.A.; visualization, W.N.; supervision, A.S.; project administration, A.S.; funding acquisition, A.S. All authors have read and agreed to the published version of the manuscript.".

Funding: This research received no external funding. The Newborn Foundation donated the pulse oximeters to the Hospital of Specialties of the Woman and the Child.

Considerations: The development of this protocol was supported by a cooperation agreement signed on the 11th of January of 
2019 between the Ministry of Health of the State of Queretaro and the Newborn Foundation partnering with the Autonomous University of Queretaro. The official ID of the agreement for the State Ministry of Health was E/CJ-002/2019.

Acknowledgments: To Dr. Ramon Chaparro, a pediatric cardiologist who dedicated his life to researching, understanding, and helping kids with heart diseases. To the Director and Co-Director of the Hospital of the Women and the Child in the City of Queretaro, Dr. Manuel Alcocer Alcocer, and Dr. Thania de Icaza

Conflicts of Interest: The authors declare no conflict of interest.

NT

Corresponding Author
Oscar San Roman Orozco, MD
MPH Candidate, Global Health
New York University
School of Global Public Health
T: US: +1 (646) 280 0740
MEX: +52 (442) 274 2901
Email:osr215@nyu.edu
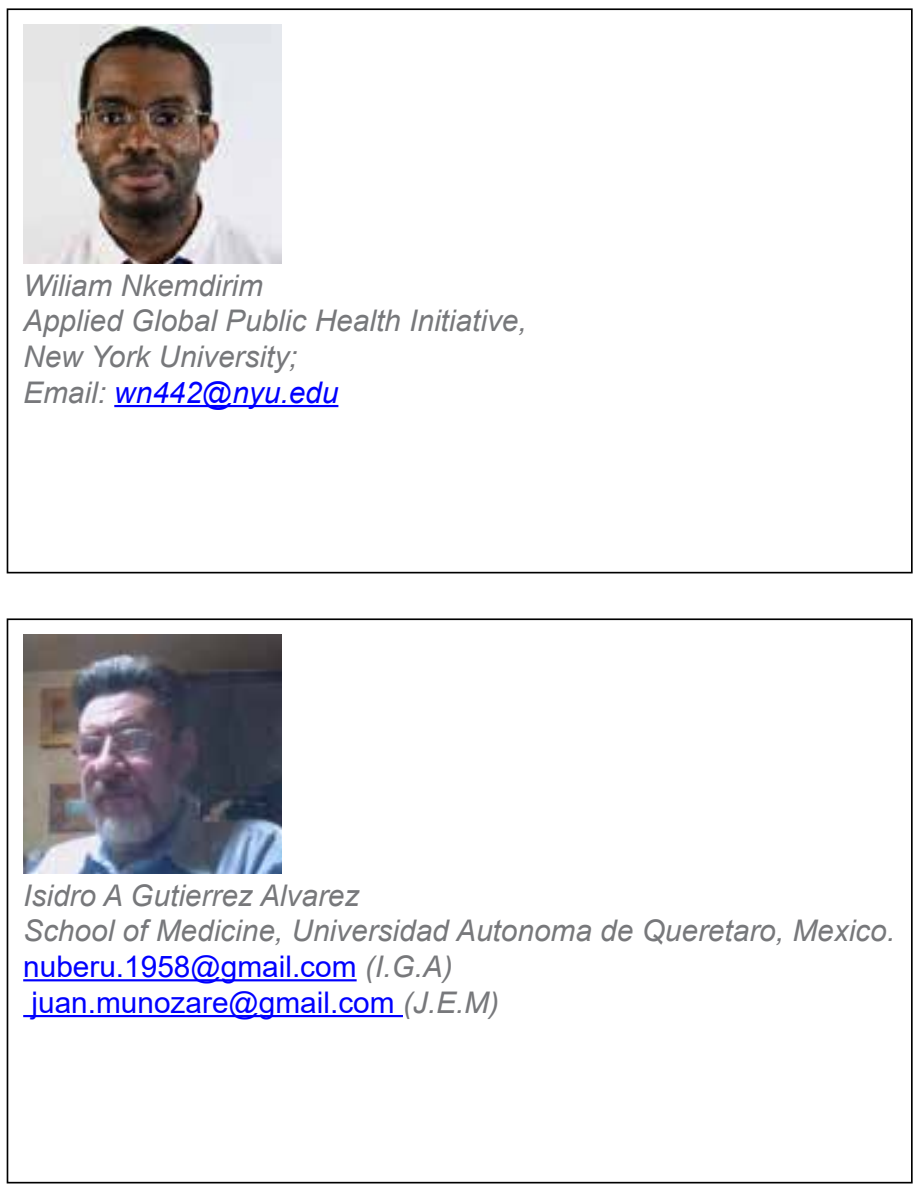

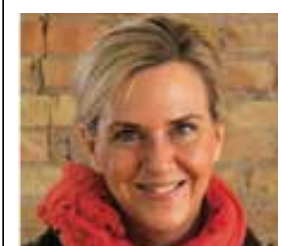

Annamarie Saarinen

Newborn Foundation, Saint Paul, MN, USA.

Email: annamarie@newbornfoundation.org

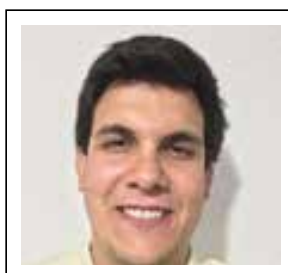

Enzo Zanella

Newborn Foundation,

Saint Paul, MN, USA.

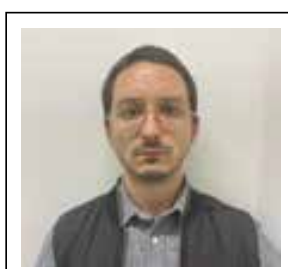

Juan E Muñoz

Newborn Foundation,

Saint Paul, MN, USA.

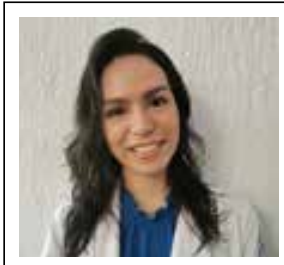

Patricia Ledesma

Newborn Foundation,

Saint Paul, MN, USA. 


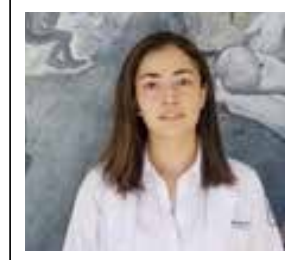

L. Alejandra Guzman

Newborn Foundation,

Saint Paul, MN, USA

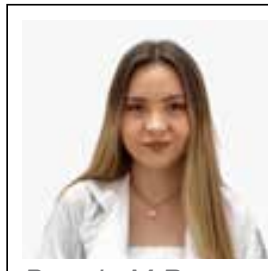

Brenda M Perez

Newborn Foundation

Saint Paul, MN, USA

\section{SAVE THE DATE}

\section{LESSONS LEARNED FROM THE NOVAVAX PHASE 3 MATERNAL VACCINATION TRIAL}

Webinar 2 - November 20th, 2020

$$
\text { 15:30 - 16:30 CEST }
$$

\section{R S V W E B I N A R S E R I E S}

F O C S Publication: Respiratory Syncytial Virus Vaccination during Pregnancy and Effects in Infants, The New England Journal of Medicine (2020) Click Here

This webinar will focus on the outcomes of the Novavax phase 3 maternal vaccination trial examining the differential effect of vaccine efficacy in HICs versus LMICs. Through interactive discussion and interview with guest speaker, prof. Shabir Madhi, participants can ask questions directly to the speaker and expand on the lessons learned from this trial in their own research.

A U D I E N C E Clinicians, researchers, pharmaceutical industry workers, global health workers, public health workers

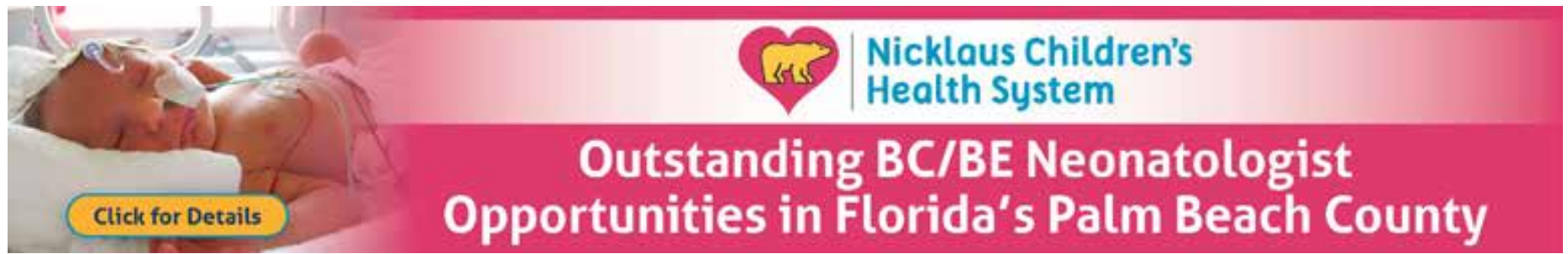

